\title{
Laproscopic and robotic management of obstructive ureteral injuries: A Review
}

\author{
Khalid Deshmukh and Gaaminepreet Singh* \\ Department of pharmacology, ISF College of Pharmacy, Moga, Punjab, India
}

\begin{abstract}
Ureteric obstruction related injuries are becoming dramatic in past decades. For there management, various therapeutic approaches are developed. Moreover, in our present review we summarized the laproscopic and robotic management techniques for obstructive ureteral injuries. Laproscopic and robotic procedures are evolved when ureteral stent treatment start to fail. Here we focused on uretero-ureterostomy and ureteroneocystostomy, psoas hitch and boari flap procedures, transureteroureterostomy, robotic reconstruction, robotic reimplantation, robotic ileal ureter and robotic autotransplantation.
\end{abstract}

\section{Introduction}

Urolithiasis, tumors, infections, post traumatic stenosis, congenital anomalies, or surgical operations are most common causes that leads to ureteric obstruction. Internal stenting with or without dilatation is the initial line of endourological therapy, which can be done retrogradely or antegradely. The benefits of stents in terms of preventing urine extravasation, re-structuring, and promoting ureteral healing must be balanced against the risk of worsening the severity of the strictures were described by certain authors [1]. Furthermore, the optimum stenting time and size are yet unknown. If endoscopic treatment fails or is contraindicated, open, laparoscopic or robotic procedures are used to rebuild the ureter after temporary urine diversion. Many factors influence obstructive ureteral treatment, the most important of which are the nature, severity, duration, and location of the obstruction. Because of the late diagnosis, a period of 6 to 3 months has been proposed as an acceptable waiting time for secondary stricture reconstruction, unless they are discovered and corrected at the time they occur, which, based on the outcomes, is the best situation for patients [2]. Although delayed diagnosis has an impact on surgical techniques and outcomes [3], the ultimate goal of therapy is to preserve renal function while reducing surgical morbidity, regardless of when the stricture is discovered.

\section{Laparoscopic uretero-ureterostomy (LUU) and uretero- neocystostomy (LUNC)}

LUU involves excision of the stenotic segment, spatulation of the ureteral ends and end-to-end anastomosis in either an interrupted or running fashion. Near-infrared fluorescence imaging with therapeutically accessible dyes like indocyanine green and methylene blue is being investigated as a new approach for ureter visualization [4]. The ureteroneocystostomy technique is used to treat distal ureteral injuries that are 3-5 cm long and near to the bladder [5]. The first successful LUU was done in 1992 by Nezhat, et al. [6]. Simmons, et al. revealed less estimated blood loss, shorter length of hospital stay in the laparoscopic group but similar patency and complication rates [7]. In another comparative analysis, De Cicco, et al. suggested that the two groups had a comparable recurrence ratio, with success rates above $90 \%$ [8].

\section{Laparoscopic psoas hitch and Boari flap}

This procedure includes three major steps: i) Mobilization of bladder to guarantee a tension-free anastomosis; ii) formation of an adequate submucosal tunnel to prevent vesicoureteral reflux; iii) implantation of the ureter into an immobilized part of the bladder to prevent kinking during emptying and filling with urine. Fugita, et al. described three cases using Boari flap without any complications or stricture recurrence observed at a mean follow-up of 11 months [9]. Castillo, et al. reported 30 cases as part of a large multi-institutional study. The overall success rate reached $96 \%$ with 32 months follow-up [10]. Abraham, et al. reported comparable results between early and delayed repair with Boari flap, however, early repair is technically more difficult [11]. Recently, Rassweiler, et al. compared open and laparoscopic methods, revealing longer operative times, lower estimated blood loss, shorter length of hospital stay for laparoscopy and equivalent success rates [12].

\section{Laparoscopic transureteroureterostomy (LTUU)}

This is a reconstructive alternative that can be used for upper and mid-ureteral strictures refractory to conventional surgical therapy. However, there are certain circumstance which render LTUU inappropriate: Chronic pyelonephritis, renal stones, idiopathic retroperitoneal fibrosis, previous radiation therapy or urosepsis are some of them. Feasibility of LTUU was first demonstrated by Dechet, et al. in nine female pigs [13]. Eight of them underwent successful LTUU as judged by excretory urography, retrograde pyelograms and

${ }^{\star}$ Correspondence to: Dr. Gaaminepreet Singh, Department of pharmacology, ISF College of Pharmacy, Moga, Punjab, India, E-mail: gpsinghcologist@hotmail.com

Received: June 23, 2021; Accepted: June 28, 2021; Published: June 30, 2021 
creatinine measurements. The only report on humans is by Piaggio, et al. who performed transperitoneal LTUU in three children [14].

\section{Robotic reconstruction}

Even though laparoscopy offers inherent benefits compared with open surgery, the Da Vinci Surgical System ${ }^{\text {mi }}$ (Intuitive Surgical) has revolutionized reconstructive urology. The rapid uptake of the robotic platform has increased surgeon comfort and has provided technical achievements including 3-D, magnified visualization, enhanced dexterity and ease of intracorporeal suturing.

\section{Robotic reimplantation with/without psoas hitch}

Whenever a longer defect up to $5 \mathrm{~cm}$ needs to be bridged, ureteral neocystostomy seems to be a realistic option combined with a vesicopsoas hitch if the defect measures up to $10 \mathrm{~cm}$. In one of the largest series of robotic upper tract reconstructions, Marien, et al. included 31 ureteroneocystostomies via an extravesical approach with $100 \%$ symptomatic and radiographic improvement [15]. Another cohort of 45 patients underwent robotic reimplantation with/without psoas hitch, with an overall success rate of $94 \%$, no conversion to open or aborted procedure and major complication rate of $3.6 \%$ (Clavien grade>III) [16].

\section{Robotic ileal ureter}

Almost 15 years after the introduction of the Da Vinci robotic platform, Brandao, et al. reported the first completely intracorporeal ileal ureter in a patient with multiple strictures [17]. An impressive total operating time of $420 \mathrm{~min}$ was partially attributed to repeated docking and undocking of the instruments. Ubrig, et al. published an initial series of seven patients which is the largest to date [18]. Common limitations of all the aforementioned studies are the low number of patients, the lack of late follow-up and their retrospective nature.

\section{Robotic autotransplantation.}

Autotransplantation represents the ultimate way to preserve renal function when complex ureteral, renovascular or malignant pathologies are encountered. Robotic autotransplantation is still in its infancy as only 11 cases have been reported worldwide (seven from Europe, three from the USA, and one from Japan) [19].

\section{Discussion}

Obstructive ureters are a relative rare but under-reported problem, often resulting from iatrogenic manipulation of the urinary tract. Treatment strategies are multifactorial, mainly depending on the time of diagnosis and extent of the defect. Therapeutic management ranges from an uncomplicated endoscopic approach to next-generation tissue engineering. The decision as to which repair to perform is often made in the operating room when the precise length of stricture and tissue tension can be readily assessed. Historically, open surgery is considered the gold standard repair method, yet it is associated with significant morbidity, complications and prolonged hospitalization. With the impressive implementation of laparoscopic and robotic surgery and the promising results already reported for pyeloplasty, it seems rational to expect similar outcomes following reconstruction of the ureter. Both routes of minimally invasive surgery offer advantages, including enhanced vision, lower blood loss, less pain, improved cosmesis, shorter hospitalization and faster return to work. The risk of complications or adverse incidents is closely correlated with the complexity of the reconstruction: the more advanced the reconstruction, the more considerable the risk. However, adhesion to open surgical principles is of utmost importance in achieving satisfactory outcomes. Reconstruction of the upper urinary tract, whether laparoscopic or robotic, is a technically demanding operation which requires a high degree of laparoscopic skills, a long learning curve and is currently carried out at specialized centers by experienced surgeons. As medical technologies constantly evolve, surgery continues to reshape and adapt to the new era.

\section{Conflicts of Interest}

The Authors report no conflicts of interest.

\section{Authors' Contributions}

Concept and study design: Khalid deshmukh and Gaaminepreet singh. Methods: Khalid deshmukh and Gaaminepreet singh. Results, analysis and conclusions: Khalid deshmukh and Gaaminepreet singh. Article preparation: Khalid deshmukh and Gaaminepreet singh. All Authors read and approved the final version of this article.

\section{References}

1. Yossepowitch O, Lifshitz DA, Dekel Y, Gross M, Keidar DM, et al. (2001) Predicting the success of retrograde stenting for managing ureteral obstruction. J Urol 166: 17461749 .

2. Ambani SN, Skupin P, Malaeb BS, Barboglio-Romo P, Stoffel JT (2019) Does early ureteroneocystostomy after iatrogenic ureteral injury jeopardize outcome? Urology 136: 245-250. [Crossref]

3. Ghali AM, El Malik EM, Ibrahim AI, Ismail G, Rashid M (1999) Ureteric injuries: Diagnosis, management, and outcome. $J$ Trauma 46: 150-158. [Crossref]

4. Slooter MD, Janssen A, Bemelman WA, Tanis PJ, Hompes R (2019) Currently available and experimental dyes for intraoperative near-infrared fluorescence imaging of the ureters: A systematic review. Tech Coloproctol 23: 305-313. [Crossref]

5. Stefanovic KB, Bukurov NS, Marinkovic JM (1991) Non-antireflux versus antireflux ureteroneocystostomy in adults. Br J Urol 67: 263-266. [Crossref]

6. Nezhat C, Nezhat F, Green B (1992) Laparoscopic treatment of obstructed ureter due to endometriosis by resection and ureteroureterostomy: A case report. J Urol 148: 865868. [Crossref]

7. Simmons MN, Gill IS, Fergany AF, Kaouk JH, Desai MM (2007) Laparoscopic ureteral reconstruction for benign stricture disease. Urology 69: 280-284. [Crossref]

8. De Cicco C, Ret Davalos ML, Van Cleynenbreugel B, Verguts J, Koninckx PR (2007) Iatrogenic ureteral lesions and repair: A review for gynecologists. J Minim Invasive Gynecol 14: 428-435. [Crossref]

9. Fugita OE, Dinlenc C, Kavoussi L (2001) The laparoscopic boari flap. J Urol 166 51-53. [Crossref]

10. Castillo OA, Travassos J, Escobar JF, Lopez-Fontana G (2013) Laparoscopic ureteral replacement by boari flap: Multi-institutional experience in 30 cases. Actas Urol Esp 37: 658-662. [Crossref]

11. Abraham GP, Das K, Ramaswami K, George DP, Abraham JJ, et al. (2011) Laparoscopic reconstruction of iatrogenic induced lower ureteric strictures: Does timing of repair influence the outcome? Indian J Urol 27: 465-469. [Crossref]

12. Rassweiler JJ, Gozen AS, Erdogru T, Sugiono M, Teber D (2007) Ureteral reimplantation for management of ureteral strictures: A retrospective comparison of laparoscopic and open techniques. Eur Urol 51: 512-522. [Crossref]

13. Dechet CB, Young MM, Segura JW (1999) Laparoscopic transureteroureterostomy: Demonstration of its feasibility in swine. J Endourol 13: 487-493. [Crossref]

14. Piaggio LA, Gonzalez R (2007) Laparoscopic transureteroureterostomy: A novel approach. J Urol 177: 2311-2314. [Crossref]

15. Marien T, Bjurlin MA, Wynia B, Bilbily M, Rao G, et al. (2015) Outcomes of roboticassisted laparoscopic upper urinary tract reconstruction: 250 consecutive patients. $B J U$ Int 116: 604-611. [Crossref] 
16. Fifer GL, Raynor MC, Selph P, Woods ME, Wallen EM, et al. (2014) Robotic uretera reconstruction distal to the ureteropelvic junction: A large single institution clinical series with short-term follow up. J Endourol 28: 1424-1428. [Crossref]

17. Brandao LF, Autorino R, Zargar H, Laydner H, Krishnan J, et al. (2014) Robotic ileal ureter: A completely intracorporeal technique. Urology 83: 951-954. [Crossref]
18. Ubrig B, Janusonis J, Paulics L, Boy A, Heiland M, et al. (2018) Functional outcome of completely intracorporeal robotic ileal ureteric replacement. Urology 114: 193-197. [Crossref]

19. Decaestecker K, Van Parys B, Van Besien J, Doumerc N, Desender L, et al. (2018) Robot-assisted kidney autotransplantation: A minimally invasive way to salvage kidneys. Eur Urol Focus 4: 198-205. [Crossref]

Copyright: $@ 2021$ Deshmukh K. This is an open-access article distributed under the terms of the Creative Commons Attribution License, which permits unrestricted use, distribution, and reproduction in any medium, provided the original author and source are credited. 